\title{
日本人正常精巣の重量拈よびサイズについての検討
}

\author{
第 1 報

\begin{tabular}{|c|c|c|c|}
\hline & 田 & 坂 & 登 \\
\hline & 平 & 賀 & 聖 \\
\hline & 北 & 村 & \\
\hline $\begin{array}{c}\text { 東海大学医学部移植学教室 I } \\
\text { (主任：佐藤授) }\end{array}$ & 飯 & 田 & 宜 \\
\hline & 黒 & 川 & 順 \\
\hline & 飛 & 田 & 美 \\
\hline & 佐 & 藤 & \\
\hline
\end{tabular}

\section{FIRST REPORT ON THE STUDIES OF THE NORMAL TESTICULAR WEIGHT AND SIZE IN JAPANESE} \\ Tomi Tasaka, Seigo Hiraga, Makoto Kitamura, Takashi Iida, Junji Kurokawa, \\ Miho Hida and Takeshi Satoh \\ Department of Transplantation 1, School of Medicine Tokai University
}

Testis weight and size of Japanese were investigated on 651 necropsy cases acquired during the years 1974 to 1984 at the department of forensic medicine, school of medicine, Tokai university. Measurements of materials were carried out within 24 hours after sudden death. However, cases with some testis lesions in the past history and with apparent abnormal testis were excluded.

On the average, the right testes were larger than the left ones in weight and width in all the age groups. The mean values of testis measurement in adult age (from 20 to 49 years) were as follows: The left testis weight was $14.53 \pm 4.07 \mathrm{gr}$, longitudinal length $4.51 \pm 0.64 \mathrm{~cm}$, transverse length $3.04 \pm$ $0.43 \mathrm{~cm}$ and width $1.47 \pm 0.3 \mathrm{~cm}$. In the right testis the weight was $15.35 \pm 4.26 \mathrm{~g}$, longitudinal length $4.53 \pm 0.61 \mathrm{~cm}$, transverse length $3.50 \pm 0.4 \mathrm{~cm}$, and width $1.55 \pm 0.33 \mathrm{~cm}$. The age group of thirties showed the maximum values in testis weight, longitudinal length and transverse length, of all age groups.

要旨：最近，日本人の精巣重量抢よびサイズ等に関して検討を行なった報告は，汪とんど見られない． 今回, われわれは, 747例の变死体剖検症例を対象として, そのらちの651例について精巣重量とサイズ の検索を行なった.

重量, 厚さは $\mathrm{p}<0.01 て ゙$ 右の方が大きく, 20 ４9歳の平均精巣重量は左 $14.53 \pm 4.07 \mathrm{~g}$, 右 $15.35 \pm 4.26$

$\mathrm{g}$, 平均サイズは左長径 $4.51 \pm 0.64 \mathrm{~cm}$, 短径 $3.04 \pm 0.43 \mathrm{~cm}$, 厚さ $1.43 \pm 0.3 \mathrm{~cm}$ で, 右長径 $4.53 \pm 0.61 \mathrm{~cm}$, 短径 $3.05 \pm 0.4 \mathrm{~cm}$, 厚さ $1.55 \pm 0.33 \mathrm{~cm}$ であった。 また両側精巣とも重量, 長径, 短径で 30 歳代が最大と の結果が得られた。

\section{はじめに}

日本人の精巣重量およびサイズ等に関して剖検症例 を対象として検索した報告は，最近の文献ではわが国 では皆無,諸外国でも注とんど見当たらない。また1961

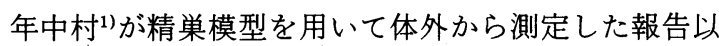

来, 生体についての精巣重量の報告も見られない。そ こで，われわれは最近の日本人の体位向上につれて, 精巣重量拉よびサイズもかなり変化しているのではな いかとの推論のもとに検討を行なったのでその成績を 報告する. 


\section{対象および方法}

昭和 49 年 6 月より，昭和 59 年 5 月までの過去 10 年間 に東海大学医学部法医学教室で解剖を行なった变死体 747例中651例を対象に精巣の測定を行なった。精巣は 摘出後，標本固定を行なら前に速やかに測定したもの で, 重量のほか精巣サイズとして長径, 短径, 厚さの 各最大部位を測定した。対象症例には生前の既往に精 巣に病変の認められないものを選択し，また剖検時に 肉眼的に病変があると思われるものは除外し，さらに 肝疾患のあるものをも除外した。

\section{結果}

651症例すべての両側精巣重量をプロットすると Fig. 1に示す通りであり，左右精巣重量の相関を検討 すると,Fig. 2の如く相関係数 0.991 という高い値で両 側精巣に対応が認められた。

両側精巣の重量を各年代ごとにプロットすると，全 年代に打いて右精巣が左精巣より重く $(\mathrm{p}<0.01)$, 精 巣重量の最大值は両側とも 30 歳代にあり, 以後は減少

Fig. 1 Bilateral testis weight and age distribution (651necropsy cases in Japan)
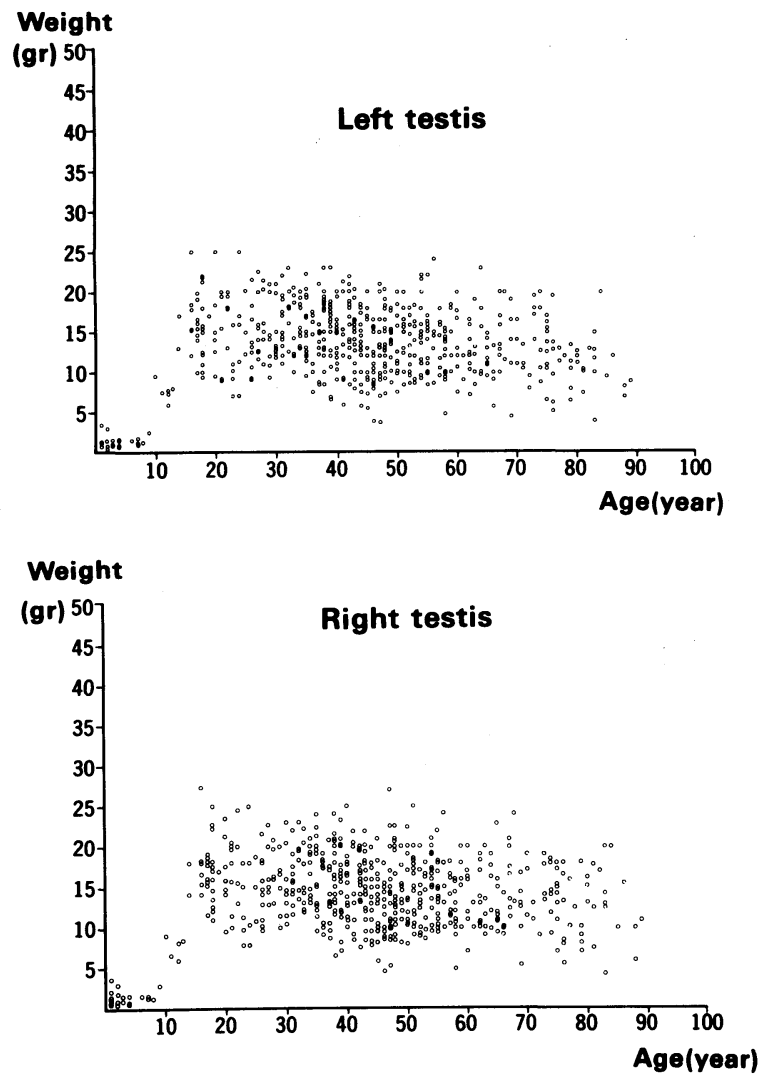

傾向を示した（Fig. 3).な初青壮年期に該当する 20 49歳の平均精巣重量 $(n=349)$ をもとめると, 左 側14.53 $\pm 4.07 \mathrm{~g}$, 右側 $15.35 \pm 4.26 \mathrm{~g}$ であった。

次に精巣のサイズに関する測定成績を示す，長径は 精巣重量と同様，30歳代に最大となるが，他の年代の 平均値との間にとくに統計学的な有意差は認められな かった。また30歳代以後は精巣重量と同様に漸减する 傾向であった。 20〜49歳の平均精巣長径は左 $4.51 \pm$ $0.64 \mathrm{~cm}$, 右 $4.53 \pm 0.61 \mathrm{~cm}$ であり, 統計的有意差はない が，右精巣の長径が大きい傾向を示した（Fig. 4).

Fig. 2 Correlation coefficient of bilateral testis weight

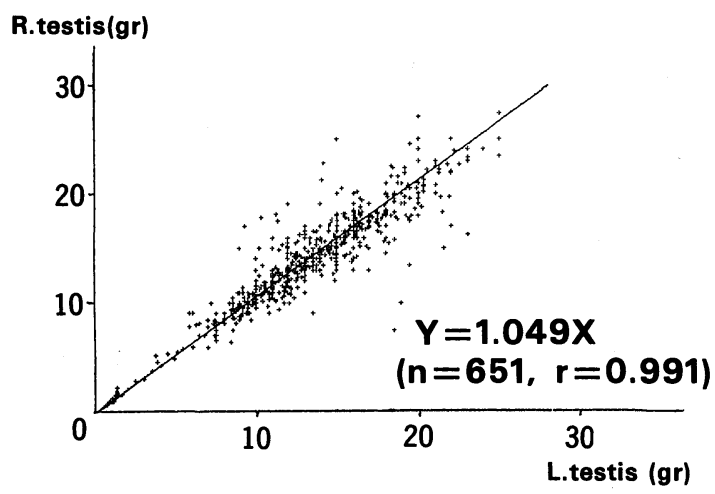

Fig. 3 Correlations of testis weight to age distribution

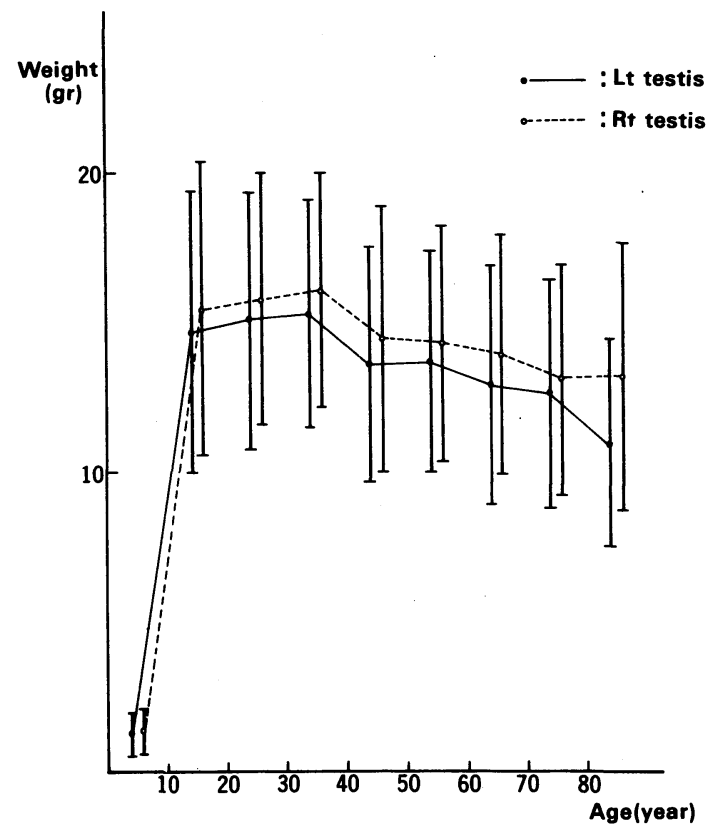


Fig. 4 Correlations of longitudinal length of the testis to age distribution

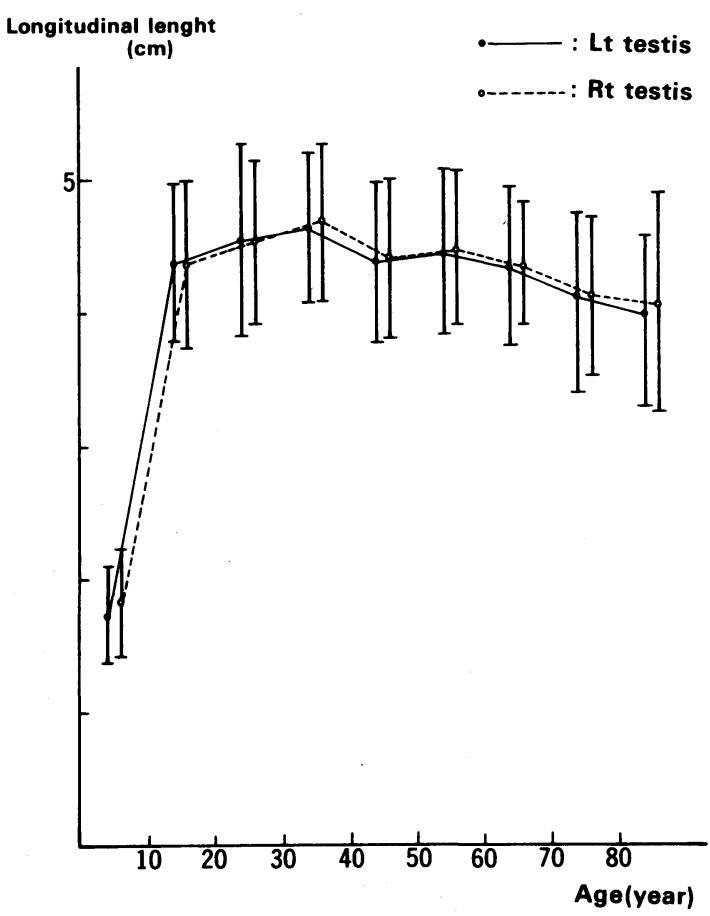

精巣の短径の測定值でも30歳代が最大であったが, 以後の年代に減少傾向は見られなかった。また $20 〜 49$

Fig. 5 Correlations of transverse length of the testis to age distribution

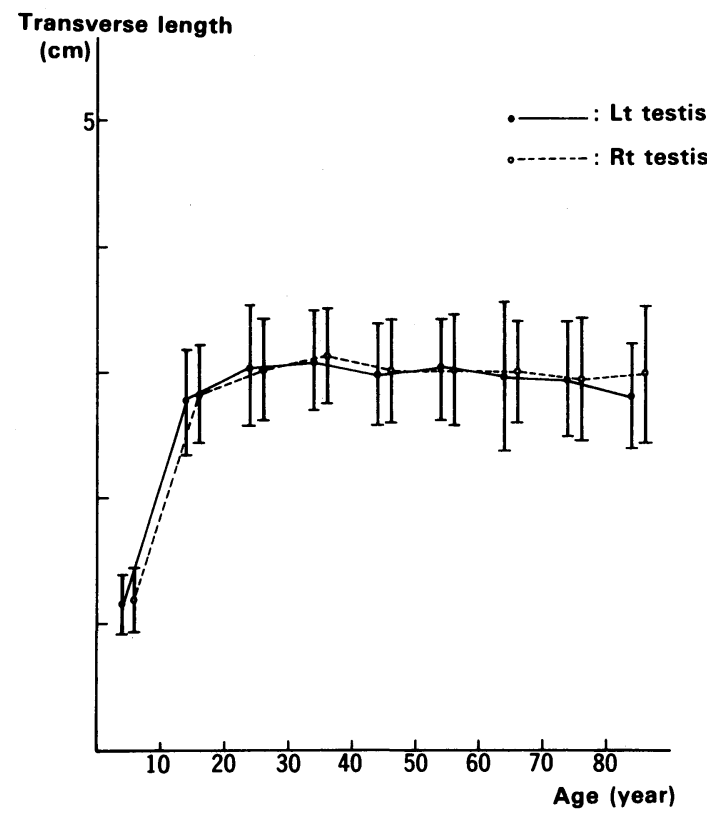

Fig. 6 Correlations of testicular length in width to age distribution

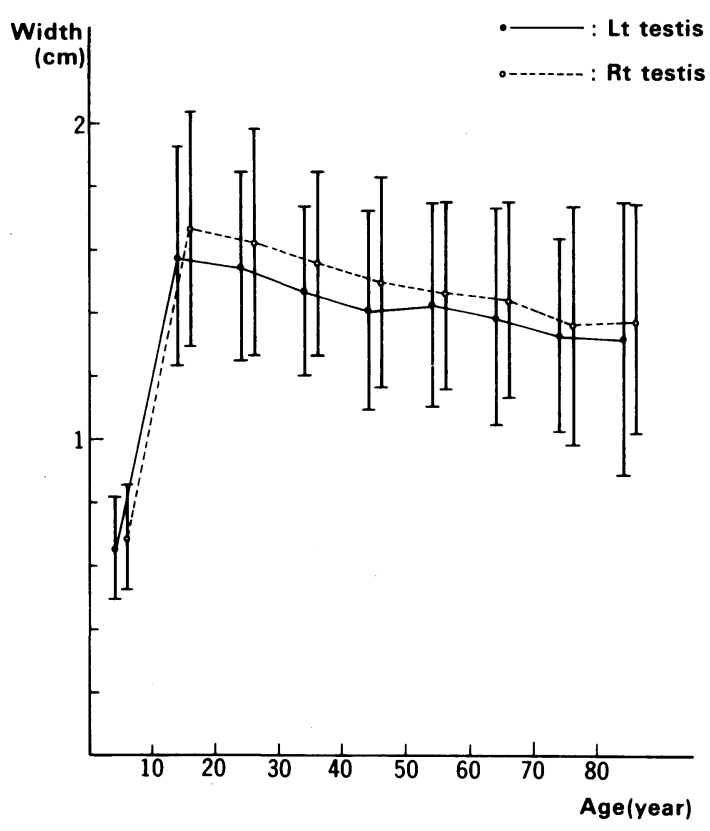

歳の平均精巣短径は左 $3.04 \pm 0.43 \mathrm{~cm}$, 右 $3.05 \pm 0.40$ cm で右の方が大きかった（Fig. 5).

精巣の厚さは10歳代が最大値を示し, 全年代におい て右側が左側より有意に大きかった（ $\mathrm{p}<0.01 ） .10$ 歳 以後は漸減し, $20 \sim 49$ 歳での厚さは左 $1.47 \pm 0.3 \mathrm{~cm}$, 右 $1.55 \pm 0.33 \mathrm{~cm}$ であった（Fig. 6).

Table 1に今回計測した20歳より89歳までの各年代 における両側精巣の重量, サイズについての実測平均 値を示す.な㨬の右端には20４9歳349症例の測定平 均値の成績を示した。この表からは 0 〜 19歳までの精 巣測定值を除外しているが，この年代の剖検症例数が 比較的少なく, 最も精巣の発育が著しい10歳代を含め た精巣の測定は月単位で行なら必要性があると考えた からである。

\section{考察}

日本人の精巣重量およびサイズについての剖検報告 は，1951年森岡2)の報告以来われわれの検索した限り では行なわれていない.1960年落合ら 3 は 1 歳から 84 歳の生体精巣100例につき病理組織所見を中心に年齢 との関係を検討している。また1961年中村 ${ }^{1)}$ は精巣模 型を使用して生体 1,518 例に対して, 体外測定を施行し ているが, この報告は精巣容積についてのものである. 中村の報告では30歳と40歳の間で精巣容積は最大に達 
Table 1 Mean values of testis weight and size in Japanese (adult : 20 89years)

\begin{tabular}{|c|c|c|c|c|c|c|c|c|c|}
\hline & age $(n)$ & $20 \sim 29(67)$ & $30 \sim 39(124)$ & 40 49(155) & 50 59(111) & $60 \sim 69(62)$ & $70 \sim 79(41)$ & 80 89 (18) & |20 49(349) \\
\hline \multirow{4}{*}{ Lt } & Wt. (gr) & $\mid 15.05 \pm 4.32$ & $15.23 \pm 3.79$ & $13.54 \pm 3.91$ & $13.56 \pm 3.68$ & $12.89 \pm 4.00$ & $12.59 \pm 3.81$ & $10.88 \pm 3.44$ & $\mid 14.53 \pm 4.07$ \\
\hline & $S_{1}(\mathrm{~cm})$ & $4.54 \pm 0.72$ & $4.64 \pm 0.56$ & 4. $38 \pm 0.60$ & $4.44 \pm 0.64$ & 4. $34 \pm 0.60$ & 4. $12 \pm 0.62$ & 3. $98 \pm 0.59$ & $4.51 \pm 0.64$ \\
\hline & $\mathrm{S}_{2}(\mathrm{~cm})$ & $3.05 \pm 0.49$ & $3.09 \pm 0.40$ & 2. $99 \pm 0.41$ & $3.05 \pm 0.38$ & $2.97 \pm 0.45$ & $2.95 \pm 0.43$ & $2.82 \pm 0.42$ & $3.04 \pm 0.43$ \\
\hline & $S_{3}(\mathrm{~cm})$ & $1.55 \pm 0.30$ & $1.47 \pm 0.27$ & $1.41 \pm 0.32$ & $1.41 \pm 0.32$ & $1.38 \pm 0.34$ & 1. $33 \pm 0.30$ & 1. $32 \pm 0.43$ & $1.47 \pm 0.3$ \\
\hline \multirow{4}{*}{ Rt } & Wt. $(g r)$ & $\mid 15.76 \pm 4.17$ & $16.06 \pm 3.94$ & $14.43 \pm 4.43$ & $14.26 \pm 3.88$ & $13.86 \pm 4.03$ & $13.01 \pm 3.86$ & 13. $10 \pm 4.47$ & $15.35 \pm 4.26$ \\
\hline & $S_{1}(\mathrm{~cm})$ & 4. $53 \pm 0.61$ & 4. $68 \pm 0.59$ & $4.40 \pm 0.60$ & $4.47 \pm 0.59$ & 4. $35 \pm 0.60$ & 4. $12 \pm 0.59$ & $4.07 \pm 0.82$ & $4.53 \pm 0.61$ \\
\hline & $S_{2}(\mathrm{~cm})$ & $3.02 \pm 0.40$ & $3.13 \pm 0.38$ & 3. $01 \pm 0.41$ & $3.03 \pm 0.44$ & 3. $01 \pm 0.41$ & 2. $95 \pm 0.49$ & $3 \pm 0.53$ & $3.05 \pm 0.4$ \\
\hline & $S_{3}(\mathrm{~cm})$ & $1.62 \pm 0.36$ & $1.59 \pm 0.29$ & $1.49 \pm 0.33$ & $1.46 \pm 0.29$ & $1.44 \pm 0.31$ & $1.36 \pm 0.38$ & $1.37 \pm 0.35$ & $1.55 \pm 0.33$ \\
\hline
\end{tabular}

\section{$S_{1}:$ longitudinal length \\ $S_{2}:$ transvers length \\ $S_{3}$ : length in width}

し，50歳頃まで左右差はないが，50歳すぎょり両側精 巣容積に差異が見られる。今回のわれわれの成績から は，精巣重量については左右に拈いて $\mathrm{p}<0.01 て ゙$ 有意 差を認め，70歳代を越えてからは左精巣重量の減少が 右よりも急な結果が得られた。 また中村によれば，精 单の発育は20歳から 25 歳で一応完了し，その後は減少 傾向を示すと報告しているが，今回の成績からは，大 体10歳代後半において精巣の重量およびサイズの発育 は完了しているものと推定される，今後は精巣重量, サイズと組織所見との関係をも検討してこの点を明ら かにしたいと考光ている。

Tillinger ${ }^{4}$ (1957)は，各年龄階層における精巣重量 平均值を $20 \sim 29$ 歳が $21.1 \mathrm{~g}, 30 \sim 39$ 歳が $20.5 \mathrm{~g}, 40 \sim 49$ 歳が21.8g, 50 ５9歳が $23.5 \mathrm{~g}, \quad 60 \sim 69$ 歳が $21.4 \mathrm{~g}$, 70〜79歳が $18.5 \mathrm{~g}$ としており，また Johnson ${ }^{5)}$ (1984) らは, 21歳から50歳の剖検89症例の精巣重量平均値を, 右 $18.9 \pm 0.5 \mathrm{~g}$, 左 $17.2 \pm 0.5 \mathrm{~g}$ とした。いずれもわれわ れの成績より若干大きい值を示しているが，今回得ら れた結果とほぼ一致した值ともいえる。

Harcourt $^{6)}$ (1981)は, Gorilla, orangutan 等につい てその体重と精巣重量の相関を見ている。われわれも 精巣重量の計測と同時に体重を測定したが結果は最大 相関係数 0.216 と低値であった. また同様に身長との結 果では, 最大相関係数は 0.399 と低值を示し, いずれも 相関性はないと考えられた。

また測定症例のうち 4 例には, 精巣重量が重いから サイズも大きいとは言いがたいものが存在した。これ は精巣内容である, 精細管, Leydig 細胞や間質組織の 密度によるものと推定されるが今後の検討課題の 1 つ
と思われる。

臨床的に精巣重量およびサイズの測定には最近 Schonfeld らの考案した精巣模型や, 超音波断層法, CT-scanを用いた生体外側よりの測定が行なわれる。 しかし，生体に打いて精巣を正確に測定することは困 難であり，実際にも生体外側測定では剖検時測定より 若干大きな値とならざるを得ない，従ってこれらの方 法による測定も真の精巣の大きさを知る目安にしかな り得ないので, 正確な日本人の年齢階層別精巣重量括 よびサイズを把握しておくことは極めて重要な問題で あると考光る。

\section{結語}

最近の日本人の体位向上に伴い，精巣の大きさにも かなりの変化が存在するのではないかとの推論のもと に, 651例の剖検症例につき年龄階層別の精巣重量, サ イズを測定し以下の結果を得た。

1. 日本人の各年代に拈ける精巣重量と厚さは統計 的有意差をもって右精巣が左精巣より大きかった。

2. 日本人の青壮年層 (20歳から49歳)の平均精巣重 量は左 $14.53 \pm 4.07 \mathrm{~g}$, 右 $15.35 \pm 4.26 \mathrm{~g}$ と左右の数值に 変動があった。

3. 日本人の青壮年層 (20歳から49歳) の精巣サイズ の平均值は左側精巣で長径 $4.51 \pm 0.64 \mathrm{~cm}$, 短径 $3.04 \pm$ $0.43 \mathrm{~cm}$, 厚さ $1.47 \pm 0.3 \mathrm{~cm}$, 右側精巣で長径 $4.53 \pm$ $0.61 \mathrm{~cm}$, 短径 $3.05 \pm 0.40 \mathrm{~cm}$, 厚さ $1.55 \pm 0.33 \mathrm{~cm}$ で あった。

4. 両側精巣とも重量, 長径, 短径は30歳代が最大值 であった。

擱筆するにあたり, 御協力頂いた東海大学医学部法医学 
教室教授平瀬文子先生に感謝の意を表します。

本論文の要旨は第31回日本泌尿器科学会西日本総会に於

いて発表した。

\section{文献}

1) 中村, 亮, 日本人男子の性器系の発育と成熟. 日泌 尿会誌, 52, 172-189, 1961.

2）森岡雄太郎：岡山医師会誌，48，2716，1936.

3) 落合京一郎, 駒瀬元治, 昼間 哲, 中村 亮, 浦野 悦郎, 福田 覚: 甶丸の生活史. 最新医学, 13 , 56-69, 1958.

4) Tillinger, K.G.: Acta Endocrinol, 24 (Suppl.), 30, 1957.

5) Jhonson, L., Petty, C.S. and Neaves, W.B. : Influence of age on sperm production and tes- ticula weight. J Reprod Fertil, 70, 211-218, 1984.

6) Harcourt, A.H., Hervey, P.H., Larson, S.G. and Short, R.V,: Testis weight, body weight and breeding system in primates. Nature, 293, 55-57, 3 September 1981.

7) David, J.: Handelsman and sergestaraj: Testicular size: The effects of aging, Malnutrition, and illness. J. Androl, 3, 144-151, 1985.

8) Boisen, E.: Testicular size and shape of 47, XXY and 47, XXY men in a Double-blind, Doublematched population survey. Am. J. Hum. Genet, 31, 697-703, 1979. 